\title{
Employment Dispute Resolution: The Case for Mediation
}

LISA B. BINGHAM

T mployment dispute resolution (EDR) addresses conflict arising out cases include complaints of discrimination under state and federal equal employment opportunity (EEO) law; wrongful discharge under state law; whistle-blower retaliation; workers' compensation; wage and hour violations; occupational safety disputes; breach of contract; alleged violations of administrative policies on performance evaluation, supervision, or assignment of duties; communication problems in the chain of command; and similar matters. These claims are often outside the scope of a collective bargaining agreement. In the employer context, programs may exist in a nonunion workplace, or they may coexist with a union grievance procedure (Lipsky, Seeber, and Fincher, 2003). However, there are also programs offered by administrative agencies and courts for resolving employment disputes. Whether employer based or third party, programs may offer a variety of interventions, including an ombuds, early neutral assessment, fact finding, peer panels, mediation, or arbitration, or some combination of these.

Research on and evaluation of EDR has been influenced by the extensive literature on voice and grievance systems (Bies, 1987; Folger, 1977; Greenberg, 1996; Lewicki, Weiss, and Lewin, 1992; Lewin, 1987, 1999; Sheppard, Lewicki, and Minton, 1992; Sitkin and Bies, 1993), labor grievance mediation and arbitration in collective bargaining (Dunlop and Zack, 1997; Zack, 1997; Feuille, 1995; Ury, Brett, and Goldberg, 1989), negotiation and dispute resolution (Carnevale and Pruitt, 1992; Wall and Lynn, 1993), procedural justice (Lind and Tyler, 1988; Lind and others, 1990; Lind, Kulik, Ambrose, and de Vera Park, 1993; Tyler, 1988), and dispute system design (Costantino and Merchant, 1996; Slaikeu and Hasson, 1998; Ury, Brett, and Goldberg, 1989). This review is limited to field and 
applied research on third-party neutral processes in conflict arising from the employment relationship outside the context of collective bargaining. (For a previous review integrating literature from collectively bargained procedures, see Bingham and Chachere, 1999.)

The structural aspects of an EDR program affect its organizational function, effectiveness, and efficiency. This review is organized around these structural elements: sector or setting; overall dispute system design, including level of self-determination and institutionalization; nature of intervention; due process protections; voluntariness; timing; and quality and characteristics of neutrals. The evaluation and field research literature suggests that mediation produces better organizational outcomes than either no intervention or an adjudicatory one like arbitration.

\section{The Sector or Setting for EDR}

Context can shape dispute resolution procedures and their results (Kolb, 1989). Thus, EDR is affected by its setting in the private, nonprofit, or public sectors. In the private sector, arbitration is the dominant process; in the public sector, mediation predominates. The U.S. General Accounting Office (USGAO, 1997) also compared alternative dispute resolution (ADR) techniques used by five private sector companies and five federal agencies. It found that private companies more frequently used arbitration, and federal agencies more frequently used mediation. The settlement rate for mediation was comparable in the private and federal sectors, ranging from 60 to 80 percent.

EDR's legal setting differs from private to public sector. In the private sector, the U.S. Supreme Court has enforced mandatory arbitration agreements for claims of discrimination in employment on the theory that the Federal Arbitration Act preempts state efforts to regulate them (Dunlop and Zack, 1997; Stone, 1999; Zack, 1997). However, in the public sector, state law varies on the authority of government to use binding arbitration. At the federal level, the Administrative Dispute Resolution Act of 1996 authorizes a wide range of processes, including mediation and arbitration, but prohibits mandatory, adhesive arbitration (Evans, 1998).

\section{Private Sector}

A large-scale study of the Fortune 1000 general and litigation counsel revealed that by 1997, 87 percent of these companies had experience using mediation and 80 percent using arbitration at least once in the three years 
preceding the survey (Lipsky, Seeber, and Fincher, 2003). Over 10 percent reported they had experience using a broad range of other processes, including mediation-arbitration, in-house grievance systems, minitrials, fact finding, peer review, and ombudspersons. However, only about 19 percent reported frequent use of mediation, and 43 percent reported occasional use. There was a similar pattern for arbitration. The majority of cases involved a determination of rights, not interests. In other words, they were disputes about existing laws or contracts or policies, not efforts to negotiate new contracts. Under 40 percent had general policies favoring use of ADR. For employment disputes, almost 79 percent reported using mediation and 62 percent reported using arbitration. Mediation was by far the preferred process across all industry types. Across industry type, those reporting use of mediation for employment disputes varied from 64 to 91 percent, but again, this represents, on balance, occasional use.

Colvin (2003) found that both institutional pressures and human resource strategies are factors driving adoption of EDR. Private sector employers adopt mandatory arbitration to avoid individual employment rights litigation and because of expanded court deferral to arbitration. Union avoidance continues to be a factor predicting processes like peer review. In addition, there is a link between the use of high-performance work systems and EDR.

\section{Federal Sector}

In the federal sector, Congress enacted the Administrative Dispute Resolution Act (ADRA) in 1990 to spur agencies to consider using alternative dispute resolution (Dunlop and Zack, 1997). Five years later, a survey showed that the vast majority of cabinet- and noncabinet-level federal agencies were experimenting with the use of mediation in personnel and employment disputes (Bingham and Wise, 1996). Only a small minority of agencies made even limited use of arbitration, largely because of concerns over loss of control and delegation of governmental authority to a private decision maker.

Of federal agencies, in 199431 percent had some form of EDR (U.S. General Accounting Office, 1995); by 1996, this increased to 49 percent (U.S. General Accounting Office, 1997). At present, Equal Employment Opportunity Commission (EEOC) regulations mandate that all agencies make EDR available for complaints of discrimination (Senger, 2003; see www.adr.gov, the gateway Web site for all information on ADR in the federal government). In 2001, there were 2.5 million federal employees, 
about 15,000 of whom used EDR in an EEO case, with settlement rates ranging from over 50 to 64 percent. Federal agencies report improved case processing time with EDR. Federal agencies average three and a half years to process an EEO complaint; through EDR, the air force averages nine months. The U.S. Postal Service (USPS) is the single largest federal employer, with over 800,000 employees; its mediations average four hours in duration and result in a case closure rate of 60 to 80 percent. Canadian public service employees also have access to employment mediation for grievances; an evaluation of that program found a 50 percent settlement rate, with outcomes including practical solutions that would not have been available through adjudicative grievance proceedings, such that both parties reported interest in using mediation in the future (Zweibel, Macfarlane, and Manwaring, 2001).

There have been efforts to estimate cost savings when the federal government uses ADR for employment cases. Agencies have compared mediation costs to fully litigating a case, a method some would criticize as based on a false assumption: that the case would not have settled on its own. The Justice Department spends on average $\$ 1,007$ to mediate and $\$ 17,000$ to litigate the typical case. The air force estimates that it saves $\$ 14,000$ and 276 labor hours when it uses EDR (Senger, 2003).

Federal agencies have also tracked disputant satisfaction with EDR. The EEOC reports that over 90 percent of the participants in its private sector EDR program said they would use the process again (Senger, 2003). The USPS reports consistent satisfaction rates of over 90 percent with the mediation process and the mediators over a period of five years during which it used mediation in ten thousand to fourteen thousand cases a year (Bingham, 2003).

\section{State and Local Government}

At the state and local government levels, there are approximately six comprehensive state offices of dispute resolution, thirty-eight offices focusing on courts, and thirty-four in universities and nonprofits (see www. policyconsensus.org). Some states have legislation similar to the federal ADRA (Texas is one of them), but many have more general authorizations as part of state administrative procedure acts. Generally, state government is lagging behind the federal government in its implementation of EDR. However, there is research or evaluation on experiments in the areas of workers' compensation for on-the-job injuries in California (Lipsky, Seeber, and Fincher, 2003), New York (Seeber, Schmidle, and Smith, 
2001), and North Carolina (Clarke, 1997); on wrongful discharge and workplace grievances in Ohio (Hebert, 1999) and South Carolina (Youngblood, Trevino, and Favia, 1992); and on discrimination complaints in Kansas (Varma and Stallworth, 2002) and Massachusetts (Kochan, Lautsch, and Bendersky, 2002).

Clarke (1997) examined a North Carolina mediation program for workers' compensation cases. He used random assignment to allocate cases to either mediation or control groups. A state mediator reviewed the file, referred it to mediation if appropriate, and forwarded a list of mediators to the parties. Parties were required to attend; mediation took from two to six hours. Mediation settled 26.1 percent of the cases. In addition, some mediation group cases settled outside mediation, bringing the total settlements to 60.8 percent. In the control group, settlements were 47.6 percent. Mediation diverted some parties from bilateral settlement, but it also diverted some parties from a hearing. The program reduced median time to disposition by 60 days, from 372 days in the control to 312 days in the mediation group. Although legal counsel was present in many cases, not all parties had legal counsel in all cases. Legal counsel and mediators surveyed generally responded favorably about the program. The New York workers' compensation EDR system also produced significant favorable results (Lipsky, Seeber, and Fincher, 2003; Seeber, Schmidle, and Smith, 2001). Researchers found substantial efficiency improvements: of two thousand cases, all were resolved short of arbitration and few went to mediation. There was a significant reduction in time to disposition: 137 fewer days.

Youngblood, Trevino, and Favia (1992) examined the operation of a South Carolina conciliation office for employees not covered by a union, civil service protection, or other legislation. A statute gave the labor commissioner broad powers to deal with industrial disputes between employers and employees: to investigate, ascertain cause, and induce voluntary settlements. Researchers examined archival records and interviewed participants to determine why at-will employees viewed their dismissal as unjust and how they viewed third-party dispute resolution. They found that participants generally felt both the process and outcome of conciliation were unfair or unjust. Only 6 percent of the employees were reemployed after conciliation; 81 percent felt the outcome was unfair (distributive justice). Employees also complained the conciliation process was unfair. There usually was no face-to-face meeting or hearing; 75 percent of interviewees were dissatisfied with this process (procedural justice). Both distributive and procedural justice contributed to low employee satisfaction. 
In Massachusetts, the Massachusetts Commission Against Discrimination (MCAD) provided mediation and arbitration for discrimination claims; it was designed in collaboration with the American Arbitration Association (AAA), which administered the program (Kochan, Lautsch, and Bendersky, 2002). Based on surveys and interviews with participants in $150 \mathrm{EDR}$ and traditional cases, researchers found about a 33 percent mediation participation rate; disputants reported the chief reason they did not use EDR was that the other party would not agree. EDR cases had a 67 percent settlement rate; non-EDR cases settled at the rate of 21 percent (Lipsky, Seeber, and Fincher, 2003). Participants estimated that they had substantial cost savings, and 77 percent reported they would use the process again.

There are substantial differences across private, federal, and state sectors in the reasons for adopting EDR programs and designs; however, there is very little comparative research. Clearly, multivariate studies on factors that lead organizations to adopt different EDR designs need to control for sector and different legal and policy contexts. The absence of this research makes it more difficult to assess the degree to which the field can make general claims from program-specific research and evaluation.

\section{Overall Design of an EDR Program for an Organization's Own Employees}

Dispute system design determines many aspects of an EDR program (Ury, Brett, and Goldberg 1989; Costantino and Merchant, 1996). These designs include integrated conflict management systems, ombuds programs, and silo or stovepipe programs. Organizations may design these programs for conflict arising in-house among employees or with customers, consumers, contractors, and others. This section focuses only on in-house systems for employment conflict.

\section{EDR at the System Level}

Employers may adopt integrated conflict management systems, ombuds programs, or silo or stovepipe programs for EDR.

Integrated Conflict Management Systems. An integrated conflict management system (ICMS) is a coordinated network of options available to people for resolving conflict in an organization (Lipsky, Seeber, and Fincher, 2003). An ICMS is easily accessible to address disputes at the earliest time, 
most appropriate level, and in the most appropriate manner; they include rights-based, interest-based, and stakeholder-based options. Finally, they focus on the causes of conflict and provide a systematic approach to preventing, managing, and resolving conflict in organizations (Gosline and others, 2001; Rowe, 1997). Examples include the Massachusetts Institute of Technology, the National Institutes of Health (NIH), and the federal Agency for Healthcare Research Quality (AHRQ).

AHRQ at the Department of Health and Human Services (HHS) supports health care research through grants and contracts to improve the quality and reduce the costs of health care. With about three hundred fulltime employees, AHRQ generates few EEO complaints. However, in 1996 and 1997, AHRQ scored the lowest among all HHS agencies on the Human Resources Quality of Worklife survey, suggesting that employees were dissatisfied with communication, trust, teamwork, and organizational structure at the agency. AHRQ used the ICMS as a model for its Ombuds program to address a broad range of workplace issues, including work environment, ethics, benefits, leadership, discipline, and research (Bingham and Nabatchi, 2003). Subsequently, AHRQ received the highest score on the 2000 Quality of Worklife Survey; previously, it ranked last within HHS. AHRQ's survey scores have increased a statistically significant amount each year since its program.

Ombuds Programs. A workplace ombuds is a neutral operating inside an organization to assist employees in resolving disputes informally through confidential means. Using qualitative interviews of key federal agency stakeholders, Meltzer (1998) found that an ombuds is likely to be most effective when the EEO office has too many non-EEO complaints; the employee assistance plan is receiving workplace complaints outside its mandate; personnel-related offices are not working together; employee morale is low; there is poor employee-management communication; significant workplace issues emerge and surprise management; there are poor labor-management relations; and there are frequent employee claims of retaliation. Meltzer also found that the agencies did not evaluate their ombuds program effectiveness but enjoyed management support.

Employers may distort the ombuds title in unilaterally adopted nonunion arbitration programs. One employer had its ombuds represent employees as their advocate in arbitration, and select the arbitrator on behalf of both parties; this resulted in repeated selection of the same arbitrator, who always ruled for management (Bingham, 1996). This structure gives at least the appearance of a conflict of interest. 
Innovative research on the ombuds program at NIH suggests that such programs may help identify systemic problems. Using reflective practice to debrief practitioners, researchers found five categories of dispute factors: difficult individuals, problematic interpersonal dynamics, NIH's scientific and organizational culture, systemic problems in specific research environments, and leadership dysfunction (Kressel and others, 2004). Because an ombuds office is small and the ombuds is often a single person, these programs are particularly difficult to evaluate empirically.

The confidential nature of the work, combined with the ease of tracing a case to the parties, makes ombudspersons sometimes reluctant to cooperate with research or evaluation. Ombuds offices vary in design to fit the organization (Kolb, 1987), which makes it hard to compare one to the next.

Silo or Stovepipe Programs. Programs are so-called silos or stovepipes when they are freestanding offices, not integrated into some other department or system for disputes. Most pilot programs start this way and become institutionalized. The U.S. Department of Agriculture (USDA) has programs across fifteen agencies, including workplace, EEO, and combined offices. Most operate as stovepipes, and as a result there are some concerns about competition and turf wars between the ADR programs and traditional complaint offices like EEO (Bingham, Pitts, and Salter, 2003). The U.S. Department of Labor (USDOL) created a stovepipe for mediating regulatory cases; it had trouble achieving permanency (Lipsky, Seeber, and Fincher, 2003; Schuyler, 1993). In contrast, management gave the USPS silo two years, followed by institutionalization within EEO; this program has achieved permanency. Clearly, how the design for an initial start-up of an EDR program affects institutionalization is a critical, underresearched issue.

\section{Control over Dispute System Design}

Control over dispute system design can affect the nature of the system and its outcomes (Bingham, 2002a, 2002b). Systems for handling employment disputes may be designed unilaterally by the employer, may be negotiated at arm's length by both parties, or may be the product of a third party with regulatory responsibility, like the EEOC.

One-Party Designs. Employers in the public sector that have designed systems generally adopt mediation or ombuds programs. However, in the private sector, employers have adopted arbitration programs. One controversy in EDR surrounds the ability of an employer to structure employment 
arbitration systems unilaterally and impose them on employees as a condition of new or continued employment. The outcomes of such systems were examined in a series of studies on the employer as a repeat user of arbitration (Bingham, 1997, 1998, 2002b; Bingham and Sarraf, 2004). Looking at a sample of actual arbitration awards decided under AAA rules, Bingham (1997a, 1998) found that employers who make repeated use of arbitration have superior outcomes compared to employers that use arbitration only once in the sample and that they are more likely to be arbitrating pursuant to unilaterally imposed personnel manuals. In addition, the relative bargaining power of the employee, operationalized as white-, blue-, or pinkcollar employment category, was also relevant to success in arbitration. White-collar employees did better (Bingham, 1997a). Employees arbitrating pursuant to unilaterally imposed personnel manuals did worse (Bingham, 1998). However, studies comparing outcomes before and after the Due Process Protocol for Mediation and Arbitration of Statutory Disputes Arising Out of the Employment Relationship (www.adr.org; Dunlop and Zack, 1997) found that the disparity between repeat player and nonrepeat player win rates declined in cases involving adhesive personnel manual clauses after the Due Process Protocol required procedural protections for employees (Bingham, 2002b; Bingham and Sarraf, 2004).

Hill (2004) created alternate formulations of the repeat player variable by examining capacity for repeat use instead of actual repeat use and replicated the result. Her explanation is that there is an "appellate effect," the result of large institutions with sophisticated human resource management operations resolving meritorious cases in house and that this cannot be isolated from the repeat player effect. This is directly related to the employer learning theory suggested by others. However, an appellate effect presumably would exist equally before and after the Due Process Protocol. The fact that this study finds evidence of different outcomes before and after the Due Process Protocol in personnel handbook cases suggests that there is more at work here than sophisticated human resource management.

One study found that employers with mandatory or binding arbitration plans are viewed less favorably than employers with voluntary or nonbinding arbitration policies (Richey, Bernardin, Tyler, and McKinney, 2001). The researchers did a laboratory experiment manipulating voluntariness and binding or nonbinding arbitration independently. A followup study of employees in a Fortune 500 company found that employees had a strong preference for voluntary over mandatory programs and for 
mediation over binding arbitration or med-arb (Richey, Garbi, and Bernardin, 2002).

Two-Party Designs. Under the general supervision of a state agency, parties to a collective bargaining agreement negotiated a system for New York workers' compensation claims; it produced significant favorable results (Lipsky, Seeber, and Fincher, 2003; Seeber, Schmidle, and Smith, 2001). These disputes arise from on-the-job injuries; they concern medical treatment, return to work, and amount and duration of benefits. There were delays in administrative adjudication, scheduling, and incentive structures for legal counsel. The EDR system focused on one union contract covering twenty-five thousand workers and included an ombudsperson, nurse advocate, mediation, and arbitration. Using before and after comparisons, researchers found substantial efficiency improvements: of two thousand cases, all were resolved short of arbitration, and few went to mediation. There was a significant reduction in time to disposition: 137 fewer days. There was decreased reliance on outside counsel; employees got their questions answered without an advocate. The new system produced comparable substantive outcomes; there was no significant reduction in employee benefits. This is a litmus test evaluators have used in the past to judge the fairness of alternatives to the public justice system.

Third-Party Designs. In the employment arena, third-party designs are generally the product of the executive branch of government. Due to concern about the constitutionality of delegating to an arbitrator the power to decide these cases, mediation is the process of choice. Third-party designs include experiments by the MCAD (Kochan, Lautsch, and Bendersky, 2002) and the EEOC (McDermott, Obar, Jose, and Bowers, 2000); workers' compensation systems in California, New York (Seeber, et al. 2001), and North Carolina (Clarke, 1997); a wrongful dismissal claim system (Youngblood, Trevino, and Favia, 1992); and mediation in Canada for discrimination complaints (Zweibel and Macfarlane, 2001). In general, third-party designs have not been subject to the same commentator criticism as one-party designs. Most agencies involve stakeholders in the design process and solicit comment through the use of focus groups and other techniques. In assessments of procedural justice, the majority of participants generally report that mediation in this context is fair. However, there has been no explicit comparison of these with one- and two-party designs to examine patterns of difference in the structural features of the resulting system. 


\section{Institutionalization, Structural Support, and Efforts to Implement}

One measure of a program's effectiveness is participation rate: Of those offered mediation or ADR, what proportion accepts? For EEO, participation rates varied widely across the various USDA agencies, with an overall department average of 23.3 percent, as contrasted with 75 percent at the USPS (Bingham, 2003); the USPS has one consistent national system integrated into the EEO function, and it conducted nationwide training and awareness efforts, including video presentations on its in-house television network. USDA key stakeholders reported that the three top incentives for using EDR were early resolution (46 percent), improving workplace climate (31.7 percent), and cost savings (28.6 percent) (Bingham, Pitts, and Salter, 2003). The top three obstacles or weaknesses were lack of awareness or appropriate marketing (42.9 percent), mistrust or skepticism about EDR (22.2 percent), and lack of resources (14.3 percent). Stakeholders recommended better marketing or improving awareness (19 percent), training managers and employees in conflict management (15.9 percent), and improving office communication or working to minimize turf wars (14.3 percent).

The USDOL had a sequence of pilot programs that it designed on a silo model for employment regulatory disputes; the USDOL is a party in an enforcement capacity. An early pilot provided mediation for wage-andhour cases (Schuyler, 1993). Using incomplete data, the USDOL found a wage-and-hour case that used EDR had lower average administrative cost and required less time than a non-EDR case. This study did not use random assignment. The pilot, though a success, failed to attract more institutional resources at USDOL. More recently, the USDOL tried another pilot in collaboration with Cornell (Lipsky, Seeber, and Fincher, 2003). The design called for the solicitor's office to refer cases under any of the 180 statutes the department has responsibility to enforce. Cornell designed the pilot, developed the roster, and administered the program. After one year of operation, the program had handled only seventeen cases, although there was a 75 percent case closure rate (cases settled or withdrawn). Similarly, participation rates were lower in the MCAD program, averaging at about one-third (Kochan, Lautsch, and Bendersky, 2002). Researchers reported problems training MCAD employees and turnover within leadership as hindering implementation of the program; they found AAA administrative services to be essential. This points to one of the problems with silo programs: their very independence can create a barrier to institutional acceptance. 


\section{Nature of the Intervention: Mediation or Arbitration}

Whether to have an ombuds, early neutral assessment, fact finding, peer panels, mediation, or arbitration, or some combination, is the critical choice in employment dispute system design. Lipsky and Seeber (1998) found that private companies used mediation because it allowed the parties to resolve the dispute themselves, gave them greater control, was a more satisfactory process, and preserved good relationships; they used arbitration because it is required by contract and better than litigation. Brett, Barsness, and Goldberg (1996) compared mediation and arbitration outcomes based on a sample of 449 cases administered by four different major ADR providers and found that mediation was less expensive and more satisfactory to the parties than arbitration.

Mediation. Employers have adopted mediation programs for nonunion workplace disputes (Bedman, 1995; Bingham, 1997b, 2003; Bingham, Chesmore, Moon, and Napoli, 2000; Bingham and Novac, 2001). State and federal agencies have adopted mediation programs for employment disputes over which they have regulatory or enforcement authority (Clarke, 1997; Kochan, Lautsch, and Bendersky, 2002; Lipsky, Seeber, and Fincher, 2003; Schuyler, 1993; Youngblood, Trevino, and Favia, 1992).

- Models of mediation: A largely unexplored area is the impact of different models of mediation on participant and organizational outcomes (Bingham, 2002a; Riskin, 2003). Mediation can be evaluative if the mediator gives an expert opinion on the merits of the dispute (Waldman, 1998). In a problem-solving or facilitative model, the mediator helps the parties identify and dovetail their interests (Fisher, Ury, and Patton, 1991; Waldman, 1998). Still less directive is transformative mediation (Bush and Folger, 1994; Folger and Bush, 1996), which focuses on empowering the parties to control all aspects of the mediation. Transformative mediators do not pressure parties to accept a settlement, but rather to clarify their own interests, goals, and choices. The mediator also fosters moments of recognition, in which each party reaches a better understanding or acknowledges the other's perspective. The USPS, the Transportation Security Administration, and Raytheon Corporation have adopted the transformative model; virtually all court- and agency-annexed programs use either facilitative or evaluative mediation.

The mediation model may influence participant and organizational outcomes, but there is limited systematic employment research comparing 
them. One study asked human resource practitioners to rate the effectiveness of different models of mediation at different stages of an EEO charge, and found they believed all models more effective precharge than in court; in general, mean effectiveness rankings fell below the midpoint on a fivepoint scale (Varma and Stallworth, 2001). Interestingly, they ranked transformative mediation more effective than facilitative or evaluative models. Unfortunately, the study had a small sample of only seventy-four; the response rate was 37 percent.

- Employer programs: The USPS mediation program REDRESS has generated the most comprehensive data (Lipsky, Seeber, and Fincher, 2003). The program uses transformative mediation (Bush and Folger, 1994). One study suggests that USPS dispute resolution specialists and mediators are generally focusing on opportunities for disputant empowerment and mutual recognition of interests, concerns, and perspectives; in the USPS design, mediators may not evaluate the case or pressure the parties to settle (Nabatchi and Bingham, 2001). Bingham (1997b, 2003) found that USPS supervisors and employees were equally satisfied with the outside neutral mediator and the process of EEO dispute mediation, and that there was the same pattern with respect to satisfaction with outcome as in other procedural justice research; complainants were less satisfied with outcomes than respondents.

The USPS database contains over 180,000 exit surveys collected since the inception of the first pilot program in 1994. Contrary to critics' suggestions that mediation is a fad or disputants' satisfaction is the product of honeymoon or Hawthorne effects, the national USPS program has produced consistently high participant satisfaction (over 90 percent with process and mediator, over 60 percent with outcome) for over five years (Bingham, 2003). Both complainants and respondents report satisfaction with how they can present their views in mediation (93 percent), can participate in the process of resolving the dispute ( 94 percent), and are treated in mediation (91 and 94 percent, respectively). On measures of respectfulness, impartiality, fairness, and performance, between 96 and 97 percent of all complainants, respondents, and their respective representatives were either satisfied or highly satisfied with the mediators. Complainants and their representatives are satisfied with the mediators' impartiality (95 percent), although the USPS created the roster, assigns individual mediators to each case, and pays the full costs of the process. This suggests that the dispute system design has successfully addressed any latent concerns regarding mediator bias. Most employees and supervisors are satisfied or 
highly satisfied with the outcome (on average, 64 percent and 69 percent, respectively). Case closure rates have exceeded 60 percent during this period.

The REDRESS program is having a significant positive impact on the USPS conflict management system. Mediation has reduced USPS formal EEO complaint caseloads (Bingham and Novac, 2001). A multivariate linear regression on formal EEO complaint filings by geographical district, number of employees, number of informal complaints, and seasonal workload complaint fluctuations found that implementation of mediation was statistically significantly related to a subsequent drop in formal complaints; these declined by almost 30 percent from their peak at fourteen thousand complaints annually in 1998. This is proof that mediation is resolving workplace conflict at an earlier stage than the traditional EEO complaint process.

Moreover, the number of complainants is decreasing. Complaints now come from 40 percent fewer people; complainants are more likely to be repeat filers (Bingham, 2003). By providing an effective voice mechanism, mediation may be averting the creation of new chronic discontents. Whether repeated use of mediation will gradually address the challenge of repeat filers, who file as many as sixty EEO complaints a year, remains to be seen.

There has been little research on how mediation affects disputants' relationships. Both employees and supervisors at the USPS reported improved supervisor listening skills through participation in the mediation pilot (Anderson and Bingham, 1997). Listening helps participants move toward recognition. In exit surveys, 61 percent of complainants and 69 percent of supervisors agreed or strongly agreed that they acknowledged as legitimate the other person's perspective, views, or interests (Bingham, 2003). While most report they acknowledged the other, the other does not always hear it; fewer than half (complainants 49 percent and supervisors 45 percent) report that the other acknowledged them. However, these percentages suggest substantial exchange of perspectives.

The most telling indicator of recognition is the apology. Apology is not always possible in litigation, because it may be an admission against interest and evidence of liability. USPS complainants and supervisors report apologies to the complainant in about 29 to 30 percent of all exit surveys (Bingham, 2003). There is less agreement about complainants apologizing to supervisors; complainants report they apologize 23 percent of the time, while supervisors hear an apology in 16 percent of their exit surveys. 
Clearly, the potential of a nonadversarial process to improve workplace relationships and climate remains a fertile area for research. For example, there are no systematic longitudinal panel studies on how participation in mediation may affect disputant conflict management skills or workplace climate. We also lack multivariate studies on the relationships between mediation and indicators of productivity, such as sick, personal, annual, unscheduled, or injury leaves; workplace injury claims for stress; unscheduled overtime; employee assistance plan referrals; and other grievance or claiming systems at the workplace. There is work in industrial relations and human resource management but not in examining EDR systems.

- Agency programs: The EEOC has institutionalized mediation and conducted extensive evaluations of its impact (Lipsky, Seeber, and Fincher, 2003; McDermott, Obar, Jose, and Bowers, 2000; Tajalli and Wright, $2002,2003)$. The EEOC had mediation programs in each of its fifty field offices by 1998. In 2000, the program was voluntary and limited to cases with established cause and a possibility of settlement before trial (Lipsky, Seeber, and Fincher, 2003). Surveys from a large representative sample revealed that 90 percent were willing to mediate again. They felt the process was fair, they had adequate information, and they had a full opportunity to present their case. Satisfaction with mediators was also high, regardless of source (Federal Mediation and Conciliation Service, EEOC, or other external mediators). However, satisfaction with outcomes was related to perceptions that the settlement was more favorable to one party. Disputants viewing themselves as the relative losers were less satisfied. The San Antonio office replicated high satisfaction findings (means over 4 on a five-point scale) and found an overall settlement rate of 62.9 percent (Tajalli and Wright, 2002). A second study found a settlement rate of 55.8 percent but a low participation rate (19.6 percent of identified cases) (Tajalli and Wright, 2003).

Arbitration. Arbitration is a quasi-judicial process in which the disputants hire a third-party decision maker, the arbitrator, to adjudicate their dispute. Generally, arbitration takes the form of an informal adversarial hearing, allowing for broad admissibility of evidence and argument and resulting in a written award (Dunlop and Zack, 1997).

The legal context for employment arbitration differs significantly from that of mediation or ombudsperson programs. Mediation and ombudsperson programs are generally voluntary as to participation and outcome. Settlement usually takes the form of an enforceable contract. Most arbitration results in a final, binding award. There is a strong federal policy of 
enforcing nonunion employment arbitration clauses, giving rise to the term mandatory arbitration (Bales, 1994). An employer can force an employee to accept arbitration of all disputes as a condition of new or continued employment, including binding arbitration for statutory claims (for a review of the law, see LeRoy and Feuille, 2003, which also contains a comprehensive empirical review of how courts have attempted to regulate predispute arbitration clauses).

Theorists have suggested that mandatory arbitration of employment discrimination claims may have adverse effects on perceptions of both procedural and distributive justice (Cohen and Domagalski, 1998). Bingham (1995) examined whether the employer or employee was the claimant and whether the arbitrator was paid or worked pro bono in 1,992 commercial arbitration cases involving employment, and found that recoveries were lower in cases where the arbitrator was paid a fee, but there was no evidence of overall proemployer bias (Bingham, 1995). However, there was evidence of due process problems in employment arbitration in 1993 (Bingham, 1996).

Howard (1995) examined mean damage awards in discrimination cases, comparing litigated and arbitrated outcomes. Arguing in favor of employment arbitration, Howard observed that plaintiffs' lawyers will take only one in twenty cases, and then only when the employee is capable of advancing a retainer and has high provable damages; thus, a quick, economical, and final process could level the playing field. Comparing samples of cases litigated in federal court (21,518 cases) with arbitration awards issued under American Arbitration Association rules (510 cases) and arbitration awards issues in the securities industry where discrimination was alleged (61 awards), he found that employees recovered something in 71 percent of pre- and posttrial cases, but in only 28 percent of tried cases. They did better in jury trials (38 percent) than nonjury trials (19 percent). In AAA arbitration, employees recovered something in 68 percent of cases, but in only 48 percent of the securities arbitration cases. The problem with these comparisons is that the cases may be apples and oranges, that is, samples of fundamentally different kinds of cases as a result of selection bias inherent in the different systems. Howard also surveyed employment lawyers, finding that while 79 to 84 percent of cases settled prior to litigation, only 31 to 44 percent of arbitrated cases settled. Defense counsel estimated attorneys' fees at $\$ 96,000$ for litigated employment discrimination cases but only $\$ 20,000$ in arbitration.

Bickner, Ver Ploeg, and Feigenbaum (1997) surveyed employers to identify arbitration components of their dispute resolution plans. They 
found that about 25 percent of employers limit arbitration to dismissal cases and that most employers adopted their plans with little or no employee input out of a concern over perceived runaway jury awards.

The field needs a well-designed empirical examination of how arbitration compares to the traditional litigation process, preferably using random assignment or matched pairs of cases. This is information policymakers need in order to decide how to address competing claims about efficiency or bias in mandatory employment arbitration.

\section{Due Process Protections}

Researchers using the organizational justice literature have long established that perceptions of fairness are an important factor in assessing the effectiveness of EDR voice systems (for reviews, see Boroff, 1991; Blancero, 1995; and Phillips, 1996). Other research shows that positive organizational outcomes are associated with more methods to voice dissatisfaction in nonunion organizations (Spencer, 1986; Huselid, 1995). Due process protections may contribute to perceptions of fairness. EDR programs may limit the right to counsel, discovery, location of process, availability of class actions, availability of written opinion or decision, and other procedural safeguards usually available in courts. Particularly in binding arbitration, the availability of procedural safeguards may make a difference; this gave rise to the Due Process Protocol.

There is limited research on the extent of due process protections in employer-designed plans. Feuille and Chachere (1995) found that plans had limits on due process. Only 55 of 110 employers allowed employees to be accompanied by a representative, and 11 of 107 employers allowed the final decisions on grievances by independent decision making by outside arbitrators. Chachere (1999 reported similar results in a study of 393 hospital ADR procedures. Few employers (18 percent) used a standard of proof for evidence, although up to 52 percent allowed employees to call witnesses. Only 224 of 393 hospitals allowed employee representation, and 54 (13 percent) allowed for independent decision making by outside arbitrators.

There is research on the role of representatives in mediation. Bingham, Kim, and Raines (2002) examined the USPS mediation program, which allows employees to bring any representative they choose, including lawyers, union representatives, professional association representatives, and friends or family. Some employees chose not to bring a representative. The study examined 7,651 mediator data tracking reports and exit surveys (7,989 complainants and 6,794 respondents), with a response rate of 70.3 percent on surveys. 
Researchers found that representation had a positive impact on settlement. The settlement rate for mediations where neither party was represented was 55 percent, whereas the settlement rate for mediations where both parties were represented was 61 percent, a statistically significant difference of 6 percent. Representation was also associated with longer mediation sessions. The mean duration for mediations where neither party was represented was 152 minutes, but that number rose to 184 minutes for mediations where both parties were represented. Researchers also compared resolution rates (full and partial) among different types of complainant representation: fellow employee, attorney, union representative, or "other." The highest rate (65 percent) occurred when complainants had a union or professional association representative. When they used fellow employees, there was a 60 percent resolution rate; complainants with attorneys had a 50 percent rate. However, cases with attorneys may be more difficult to settle because of attorney fees, making nonmonetary resolutions difficult. Attorneys may also hope to recover monetary damages in adjudication. Researchers have no way of assessing the relative merits of complaints across representation categories.

Representation also affected participant satisfaction with mediation fairness. Of complainants represented by union or professional associations, 91 percent reported being very or somewhat satisfied with mediation fairness, while 88 percent of those represented by fellow employees agreed, and only 76 percent of those with attorneys were satisfied. However, cases with attorney representatives had the lowest rate of resolution, and resolution correlates with perceptions of fairness. Complainants with no representation reported a 91 percent total satisfaction rate, with 67 percent reporting that they were "very satisfied." Participant satisfaction was generally high with all representatives. Allowing participants to bring whatever representative they prefer had no adverse impact on the program.

Varma and Stallworth (2002) surveyed human rights disputants who used mediation through a Kansas state program that employed an outside service provider. Again, there is a small sample size of forty-seven and a low response rate (17 percent), but the survey was comprehensive. Overall satisfaction rates averaged from 3.24 to 4.18 on a five-point scale $(5=$ very satisfied). Researchers found that attorney-represented clients had slightly higher satisfaction with the mediation process but slightly lower satisfaction with the mediation outcome than unrepresented or selfrepresented disputants. However, consistent with the USPS study, unrepresented or self-represented disputants reported higher satisfaction with 
their opportunity to present their side of the dispute and level of participation. Perceptions of fairness were the same for both groups. Attorneyrepresented disputants reported lower satisfaction with mediators' skills. The majority of both were happy to have a mediation provider appoint the mediator rather than select the mediator themselves. The more experience they had with mediation, the higher were their levels of satisfaction.

\section{Voluntary, Opt-Out, or Mandatory Interventions}

Brett, Barsness, and Goldberg (1996) found that mediation settled about 78 percent of cases including employment contract disputes, whether mandatory or voluntary. The USPS program is voluntary for complainants, but mandatory for the respondents as representatives of the organization; it has a 75 percent participation rate (Bingham, 2003). The MCAD program was entirely voluntary; its participation rate was about 33 percent because both disputants did not always agree to use the process (Kochan, Lautsch, and Bendersky, 2002). Court-annexed ADR research suggests that opt-out programs will generate participation almost as high as mandatory ones. Human resource practitioners reported support for legislation mandating participation in mediation by both parties, even where only one party expressed a desire to mediate (Varma and Stallworth, 2001).

\section{Timing of the Intervention}

The timing of an intervention may affect program-level outcomes. The intervention may occur anytime in a case; most often, it coincides with the four classic points of settlement: before a written complaint, immediately after a written complaint, after discovery is completed, or on the eve of trial. An intervention may affect all subsequent steps; mediation may occur in the shadow of arbitration (Dunlop and Zack, 1997). Federal EEO settlement rates vary with when ADR occurs: 56.1 percent at the informal complaint, 64.3 percent at the formal complaint, and over 50 percent in federal court (Senger, 2003). In federal government civil litigation, including employment cases, a multivariate analysis determined that earlier ADR correlated with shorter time to disposition (Bingham, Nabatchi, Jackman, and Senger, 2004). Using matched pairs, it showed no statistically significant differences between ADR and litigation for the outcome of a case, defined as the ratio of relief recovered to amount in the demand. 
Varma and Stallworth (2001) found that human resource practitioners believed EEO mediation was most effective used early in cases other than dismissal. Similarly, a survey of human rights disputants revealed a strong correlation between early mediation and higher satisfaction with process, mediator skills, and outcome (Varma and Stallworth, 2002).

\section{The Nature, Training, Qualifications, or Demographics of the Neutrals}

Third parties come from a variety of backgrounds and institutions. In employment programs, they may be lawyers, businesspeople, counselors, clergy, psychologists, social workers, peers, or volunteers. Little research systematically compares third parties along any of these dimensions or on demographic lines. Commentators have suggested that while there may be core common skills for high-quality mediators (including substantive knowledge, experience, facilitation skills, breadth of approach, communication and problem-solving skills), the skills necessary may vary depending on case context (Mareschal, 1998).

\section{Demographics}

There is debate over whether administrators should match a third party to disputants based on race, ethnicity, gender, or other demographic variables. Varma and Stallworth (2002) found minority disputants more strongly agreed that the mediator's race makes a difference. There is limited research on the demographics of disputants; one evaluation found that females decline mediation at the EEOC more than males do (Tajalli and Wright, 2003), but otherwise found no relationship between gender and employer sector (public or private). One study found no relationship between human rights disputants' income and satisfaction with mediation, but found that females were more satisfied overall than males and that whites were more satisfied than nonwhites (Varma and Stallworth, 2002).

Inside versus Outside Neutrals

During 1995 to 1997, some USPS regions implemented an inside-neutral mediation model. Inside neutrals are fellow employees trained as mediators. Outside neutrals are outside hired contractors. Generally, USPS inside neutrals were employees who administered the EEO complaint process. In 1998, all regions began using the national outside neutral model, with 
independent contractors trained in transformative mediation under the supervision of Robert A. Baruch Bush and Joseph Folger. This allowed a direct comparison of participant judgments of the two models (Bingham, Chesmore, Moon, and Napoli, 2000). Participants reported higher satisfaction with the outside mediators than the insiders; they reported full or partial resolution in 75 percent of the surveys in the outside model but in only 56 percent in the inside model, despite case selection bias in the inside model designed to produce settlements by identifying cases perceived as easier to resolve. Those who participated in the inside model were statistically significantly less satisfied with the fairness of the process, mediator impartiality and fairness, and mediator skill and performance.

However, in the EEOC San Antonio District, researchers found that EEOC inside neutrals outperformed outsiders in a third-party design (Tajalli and Wright, 2002). In this case, the insiders were independent of both employer and employee. The inside neutrals had a higher resolution rate (69.6 percent) than the outsiders (55.7 percent). Moreover, they found participants were statistically significantly more satisfied with inside neutrals on every indicator of process and mediator performance. Inside EEOC mediators might be perceived as having more power to influence the disposition of the complaint if it failed to settle; these dynamics might explain both higher satisfaction and resolution rates for insiders. However, these results must be treated with some caution because EEOC staff had access to the surveys; they were not entirely confidential. This too could skew responses in favor of the insiders.

\section{Shared Neutrals}

Hebert (1999) evaluated shared neutrals in an Ohio pilot program. Three state agencies contributed employees who were trained as mediators and comediated. Researchers surveyed mediators, participants, and agency coordinators, with response rates ranging from 48 to 63 percent, but the overall sample size was low (twenty-nine for three groups). Almost 90 percent of mediated cases reached full settlement; the remaining cases settled in part. Shared neutrals had positive views of the comediation model, feeling that it made mediation go more quickly, smoothly, and successfully. Disputant surveys reported mediators were both facilitative and evaluative.

\section{Arbitration Panels}

Bingham and Mesch (2000) used a hypothetical employee dismissal case to examine differences across four groups of actual arbitrators: AAA labor 
arbitrators, National Academy of Arbitrators (NAA) members, AAA Commercial panel for employment, and graduate students. They found that employment arbitrators reinstate employees less frequently than labor arbitrators, NAA members, or students. However, when they controlled for arbitrator characteristics such as education and experience, this difference was no longer significant. The result suggested systematic differences in the arbitrator panels.

\section{The Future and Opportunities for EDR Research}

Few studies in this review use multivariate techniques to answer certain questions critical to policymakers. There are two major sets of questions that call out for ongoing research: those regarding the most effective dispute system design (DSD) and those addressing the impact of EDR on justice. Underresearched questions about DSD include what dispute system design is most effective for enhancing interest-based dispute resolution, improving workplace climate, increasing productivity, and reducing rightsbased complaint filing and claiming. What about the impact of EDR on personal efficacy and the relationship between disputants? Moreover, does the best dispute system design depend on context? What factors predict adoption of a particular dispute system design in the public, private, or nonprofit sector?

The second set of questions that should concern policymakers explores the impact of private dispute resolution systems on public law and social justice. Few of the cited studies answer EDR critics' concerns that private processes are ways to convert discourse about civil rights of importance to our public community into negotiation about personal interests. How would we know whether EDR is undermining enforcement of public law? The answer to these questions would depend on large-scale macrojustice studies, that is, quantitative research comparing the outcomes of similarly situated cases in EDR and the public justice system or allowing for random assignment between the two. We have no adequate studies like this to date.

There are real barriers to conducting this research, but they are not insurmountable. EDR processes are generally confidential; this distinguishes them from the public justice system. Research requires some degree of disclosure. There are a few public federal sources of data, for example, those maintained by the EEOC on federal agency ADR use for cases of employment discrimination. However, there are virtually no data on private employers. Employers are concerned that system-level data might get 
used against them in litigation. For example, what if system-level data reveal that female claimants get higher dollar amount settlements than minority claimants? While statistically significant, the difference might be legally meaningless, but the mere prospect has caused some employers to refuse to collect the data, since they cannot be forced to disclose what they do not have. Moreover, ADR service providers are reluctant to release data for research that may adversely affect their ability to market their services.

This is a structural impediment to the next generation of EDR research: How can the field collect data in a way that will minimize an organization's exposure to risk? This very structural impediment provides an opportunity for foundations and government organizations that would support the research to make a significant difference. It is at least in theory possible to pool EDR data. It is possible for key stakeholders to negotiate an agreement that analyses of this pooled data would not identify an individual $A D R$ provider or employer.

There is already precedent for national players in EDR to negotiate agreements that shape the field. The Due Process Protocol is one such agreement involving major third-party providers and professional organizations of mediators and arbitrators. Similarly, there is a national Alliance for Education in Dispute Resolution administered through Cornell University's School of Industrial and Labor Relations. The solution to this structural impediment requires a national alliance to create a repository of data on EDR. While archives of selected arbitration awards and other documents exist (notably at Cornell), the few electronic databases in which there are comprehensive case data are proprietary, that is, they represent trade secrets of the organizations that created them. A negotiated agreement would have to address what entity should house the repository, protections of confidentiality for organizations providing the data, and conditions for access to the data set. Until we have better sources of data, we will have trouble answering some of the most important EDR research questions.

\section{Conclusion}

A fair reading of this substantial and growing body of research suggests that the case has been made for mediation as compared to arbitration in the field of employment disputes. It is perceived as fairer and consistently produces high satisfaction and settlement rates among disputants, and there is growing evidence that a well-designed program may produce 
efficiencies in terms of dispute processing time and early resolution of employment-related conflict. There is no evidence to date that arbitration produces these efficiencies. Moreover, there is at least preliminary evidence that mediation produces upstream effects in terms of disputants' conflict management skills. There is no similar evidence for arbitration. At the workplace, mediation works.

We cannot yet answer all the questions policymakers should ask us about the function of EDR systems. We do not have adequate quantitative, multivariate research on what factors best predict the adoption, design, and function of dispute resolution systems and what designs produce the best outcomes. We cannot answer questions on the impact of these private systems on public justice. This research will require better data. To get better data, the field needs to explore the possibilities of collaboration.

\section{References}

Anderson, J. F., and Bingham, L. B. "Upstream Effects from Mediation of Workplace Disputes: Some Preliminary Evidence from the USPS.” Labor Law Journal, 1997, 48, 601-615.

Bales, R. A New Direction for American Labor Law: Individual Autonomy and the Compulsory Arbitration of Individual Employment Rights. 30 Hous. L. Rev. 1863 (1994).

Bedman, W. L. "From Litigation to ADR: Brown and Root's Experience." Dispute Resolution Journal, 1995, 50 (4), 8-14.

Bickner, M. L., Ver Ploeg, C., and Feigenbaum, C. "Developments in Employment Arbitration: Analysis of a New Survey of Employment Arbitration Programs." Dispute Resolution Journal, 1997, 52 (1), 8-15, 78-84.

Bies, R. J. "The Predicament of Injustice: The Management of Moral Outrage." In L. L. Cummings and B. M. Staw (eds.), Research in Organizational Behavior, 9. Greenwich, Conn.: JAI Press, 1987.

Bingham, L. B. "Is There a Bias in Arbitration of Nonunion Employment Disputes? An Analysis of Actual Cases and Outcomes." International Journal of Conflict Management, 1995, 6 (4), 369-386.

Bingham, L. B. "Emerging Due Process Concerns in Employment Arbitration." Labor Law Journal, 1996, 47 (2), 108-126.

Bingham, L. B. "Employment Arbitration: The Repeat Player Effect." Employee Rights and Employment Policy Journal, 1997a, 1 (1), 189-220.

Bingham, L. B. "Mediating Employment Disputes: Perceptions of Redress at the United States Postal Service." Review of Public Personnel Administration, 1997b, 17 (2), 20-30.

Bingham, L. B. "On Repeat Players, Adhesive Contracts, and the Use of Statistics in Judicial Review of Arbitration Awards." McGeorge Law Review, 1998, 29 (2), 223-260. 
Bingham, L. B. "Why Suppose? Let's Find Out: A Public Policy Research Program on Dispute Resolution.” Journal of Dispute Resolution, 2002a, 2002 (1), 101-126.

Bingham, L. B. "Self-Determination in Dispute System Design and Employment Arbitration." University of Miami Law Review, 2002b, 56 (4), 873-908.

Bingham, L. B. Mediation at Work: Transforming Workplace Conflict at the United States Postal Service. Washington, D.C.: IBM Center for the Business of Government, 2003.

Bingham, L. B., and Chachere, D. R. "Dispute Resolution in Employment: The Need for Research.” In A. E. Eaton and J. H. Keefe (eds.), 1999 Industrial Relations Research Association Research Volume: Employment Dispute Resolution and Worker Rights in the Changing Workplace. Champaign, Ill.: Industrial Relations Research Association, 1999.

Bingham, L. B., Chesmore, G., Moon, Y., and Napoli, L. M. "Mediating Employment Disputes at the United States Postal Service: A Comparison of In-House and Outside Neutral Mediators." Review of Public Personnel Administration, 2000, 20 (1), 5-19.

Bingham, L. B., Kim, K., and Raines, S. "Employment Mediation: Exploring the Role of Representation at the USPS." Ohio State Journal of Dispute Resolution, 2002, 17 (2), 341-378.

Bingham, L. B., and Mesch, D. "Decision-Making in Employment and Labor Arbitration." Industrial Relations, 2000, 39 (4), 671-694.

Bingham, L. B., and Nabatchi, T. "Dispute System Design in Organizations." In W. J. Pammer Jr. and J. Killian (eds.), The Handbook of Conflict Management. New York: Marcel Dekker, 2003.

Bingham, L. B., Nabatchi, T., Jackman, M. S., and Senger, J. M. Before the Alternative Dispute Resolution Act of 1998: Comparing Litigation and ADR When the Federal Government Is a Civil Litigant. Bloomington: Indiana Conflict Resolution Institute, 2004.

Bingham, L. B., and Novac, M. C. "Mediation's Impact on Formal Complaint Filing: Before and After the REDRESS Program at the United States Postal Service." Review of Public Personnel Administration, 2001, 21 (4), 308-331.

Bingham, L. B., Pitts, D., and Salter, C. R. Incentives, Obstacles and Barriers to Alternative Dispute Resolution Use at the U.S. Department of Agriculture. Bloomington: Indiana Conflict Resolution Institute, 2003.

Bingham, L. B., and Sarraf, S. "Employment Arbitration Before and After the Due Process Protocol for Mediation and Arbitration of Statutory Disputes Arising Out of Employment: Preliminary Evidence That Self-Regulation Makes a Difference." In S. Estreicher and D. Sherwyn (eds.), Alternative Dispute Resolution in the Employment Arena: Proceedings of New York University Fifty-Third Annual Conference on Labor. Norwell, Mass.: Kluwer, 2004.

Bingham, L. B., and Wise, C. R. "The Administrative Dispute Resolution Act of 1990: How Do We Evaluate Its Success?" Journal of Public Administration, Research and Theory, 1996, 6 (3), 383-414. 
Blancero, D. "Non-Union Grievance Systems: Systems Characteristics and Fairness Perceptions." Academy of Management Best Papers Proceedings, 1995, 38 (1), 84-88.

Boroff, K. E. "Measuring the Perception of the Effectiveness of a Workplace Complaint System.” In D. Sockell, D. Lewin, and D. Lipsky (eds.), Advances in Industrial Relations, 5. Greenwich, Conn.: JAI Press, 1991.

Brett, J. M., Barsness, Z. I., and Goldberg, S. B. "The Effectiveness of Mediation: An Independent Analysis of Cases Handled by Four Major Service Providers." Negotiation Journal, 1996, 12 (3), 259-269.

Briggs, S., and Gundry, L. "The Human Dimensions of Grievance Peer Review." Journal of Collective Negotiations in the Public Sector, 1994, 23 (2), 97-113.

Bush, R.A.B., and Folger, J. The Promise of Mediation: Responding to Conflict Through Empowerment and Recognition. San Francisco: Jossey-Bass, 1994.

Carnevale, P. J., and Pruitt, D. G. "Negotiation and Mediation." Annual Review of Psychology, 1992, 43, 521-582.

Chachere, D. R. "Does Employee Voice Reduce Turnover? Some Evidence from Nonunion Grievance Procedures." Presented at the Industrial Relations Research Association Annual Meeting, New Orleans, January 5, 1999.

Child, J. "Predicting and Understanding Organizational Structure." Administrative Science Quarterly, 1973, 18, 168-185.

Clarke, S. H. "Mandatory Mediation in On-the-Job Injury Cases." Popular Government, 1997, 63 (1), 19-26.

Cohen, C. F., and Domagalski, T. "The Effects of Mandatory Arbitration of Employment Discrimination Claims: Perceptions of Justice and Suggestions for Change." Employee Responsibilities and Rights Journal, 1998, 11 (1), 27-40.

Colvin, A.J.S. "Institutional Pressures, Human Resource Strategies, and the Rise of Nonunion Dispute Resolution Procedures." Industrial and Labor Relations Review, 2003, 56 (3), 375-391.

Costantino, C. A., and Merchant, C. S. Designing Conflict Management Systems: A Guide to Creating Productive and Healthy Organizations. San Francisco: JosseyBass, 1996.

Dunlop, J. T., and Zack, A. M. The Mediation and Arbitration of Employment Disputes. San Francisco: Jossey-Bass, 1997.

Evans, R. J. "Notes and Comments: The Administrative Dispute Resolution Act of 1996: Improving Federal Agency Use of Alternative Dispute Resolution Processes." Administrative Law Review, 1998, 50 (1), 217-233.

Feuille, P. "Dispute Resolution Frontiers in the Unionized Workplace." In S. E. Gleason (ed.), Workplace Dispute Resolution: Directions for the Twenty-First Century. East Lansing: Michigan State University Press, 1995.

Feuille, P., and Chachere, D. R. "Looking Fair or Being Fair: Remedial Voice Procedures in Nonunion Workplaces." Journal of Management, 1995, 21 (1), 27-42. 
Fisher, R., Ury, W., and Patton, B. Getting to Yes. (2nd ed.) New York: Penguin Books, 1991.

Folger, J. P., and Bush, R.A.B, "Transformative Mediation and Third-Party Intervention: Ten Hallmarks of a Transformative Approach to Practice." Mediation Quarterly, 1996, 13 (4), 263-278.

Folger, R. "Distributive and Procedural Justice: Combined Impact of 'Voice' and Improvement on Experience Inequity." Journal of Personality and Social Psychology, 1977, 35, 108-119.

Gosline, A., and others. Designing Integrated Conflict Management Systems: Guidelines for Practitioners and Decision Makers in Organizations. Ithaca, N.Y.: Cornell/PERC Institute on Conflict Resolution, 2001.

Greenberg, J. The Quest for Justice on the Job: Essays and Experiments. Thousand Oaks, Calif.: Sage, 1996.

Hebert, C. "Establishing and Evaluating a Workplace Mediation Pilot Project: An Ohio Case Study." Ohio State Journal on Dispute Resolution, 1999, 14 (2), 415-480.

Hill, E. "Employment Arbitration Under the Auspices of the American Arbitration Association: An Empirical Study.” In S. Estreicher and D. Sherwyn (eds.), Alternative Dispute Resolution in the Employment Arena: Proceedings of New York University Fifty-Third Annual Conference on Labor. Norwell, Mass.: Kluwer, 2004.

Howard, W. M. "Arbitrating Claims of Employment Discrimination: What Really Does Happen? What Really Should Happen?" Dispute Resolution Journal, 1995, 50 (4), 40-50.

Huselid, M. A. "The Impact of Human Resource Management Practices on Turnover and Productivity." Academy of Management Journal, 1995, 38 (3), 635-672.

Kochan, T. A., Lautsch, B. A., and Bendersky, C. "An Evaluation of the Massachusetts Commission Against Discrimination Alternative Dispute Resolution Program." Harvard Negotiation Law Review, 2002, 5, 233-278.

Kolb, D. M. "Corporate Ombudsman and Organization Conflict Resolution." Journal of Conflict Resolution, 1987, 31 (4), 673-691.

Kolb, D. M. "How Existing Procedures Shape Alternatives: The Case of Grievance Mediation.” Journal of Dispute Resolution, 1989, 1989, 59-87.

Kressel, K., and others. "Sources of Destructive Conflict in Scientific Research: Findings Using the Reflective Case Study Method." Paper presented at the Seventeenth Annual Conference of the International Association for Conflict Management, Pittsburgh, June 2004.

LeRoy, M. H., and Feuille, P. "Judicial Enforcement of Predispute Arbitration Agreements: Back to the Future." Ohio State Journal on Dispute Resolution, 2003, 18 (2), 249-341.

Lewicki, R. J., Weiss, S. E., and Lewin, D. "Models of Conflict, Negotiation and Third Party Intervention: A Review and Synthesis." Journal of Organizational Behavior, 1992, 13, 209-252. 
Lewin, D. "Dispute Resolution in the Nonunion Firm: A Theoretical and Empirical Analysis.” Journal of Conflict Resolution, 1987, 31 (3), 465-502.

Lewin, D. "Theoretical and Empirical Research on the Grievance Procedure and Arbitration: A Critical Review.” In A. E. Eaton and J. H. Keefe (eds.), 1999 Industrial Relations Research Association Research Volume: Employment Dispute Resolution and Worker Rights in the Changing Workplace. Champaign, Ill.: Industrial Relations Research Association, 1999.

Lind, E. A., Kulik, C. T., Ambrose, M., and de Vera Park, M. V. "Individual and Corporate Dispute Resolution: Using Procedural Fairness as a Decision Heuristic." Administrative Science Quarterly, 1993, 38, 224-251.

Lind, E. A., and Tyler, T. R. The Social Psychology of Procedural Justice. New York: Plenum Press, 1988.

Lind, E. A., and others. "In the Eye of the Beholder: Tort Litigants' Evaluations of Their Experiences in the Civil Justice System." Law and Society Review, 1990, 24 (4), 953-996.

Lipsky, D. B., and Seeber, R. L. "In Search of Control: The Corporate Embrace of ADR." University of Pennsylvania Journal of Labor and Employment Law, 1998, 1 (1), 133-157.

Lipsky, D. B., Seeber, R. L., and Fincher, R. D. Emerging Systems for Managing Workplace Conflict: Lessons from American Corporations for Managers and Dispute Resolution Professionals. San Francisco: Jossey-Bass, 2003.

Mareschal, P. M. "Providing High Quality Mediation: Insights from the Federal Mediation and Conciliation Service." Review of Public Personnel Administration, 1998, 18 (4), 55-67.

McDermott, E. P., Obar, R., Jose, A., and Bowers, M. An Evaluation of the Equal Employment Opportunity Commission Mediation Program. Washington, D.C.: Equal Employment Opportunity Commission, 2000.

Meltzer, D. L. "The Federal Workplace Ombuds." Ohio State Journal on Dispute Resolution, 1998, 13, 549-609.

Nabatchi, T., and Bingham, L. B. "Transformative Mediation in the United States Postal Service REDRESS Program: Observations of ADR Specialists.” Hofstra Labor and Employment Law Journal, 2001, 18 (2), 399-427.

Phillips, V. "Mediation: The Influence of Style and Gender on Disputants' Perception of Justice." New Zealand Journal of Industrial Relations, 1996, 21 (3), 297-311.

Richey, B., Bernardin, H. J., Tyler, C. L., and McKinney, N. "The Effect of Arbitration Program Characteristics on Applicants' Intentions Toward Potential Employers." Journal of Applied Psychology, 2001, 86 (5), 1006-1013.

Richey, B., Garbi, E., and Bernardin, H. J. "Is Alternative Justice Just: ADR Program Characteristics and Employee Fairness and Trust Perceptions." Unpublished manuscript, 2002.

Riskin, L. L. "Decisionmaking in Mediation: The New Old Grid and the New Grid System.” Notre Dame Law Review, 2003, 79 (1), 1-53.

Rowe, M. P. "Dispute Resolution in the Non-Union Environment: An Evolution Toward Integrated Systems for Conflict Management?” In S. E. Gleason (ed.), 
Workplace Dispute Resolution: Directions for the Twenty-First Century. East Lansing, Mich.: State University Press, 1997.

Schuyler, M. L. A Cost Analysis of the Department of Labor's Philadelphia ADR Pilot Project. Washington, D.C.: U.S. Department of Labor, 1993.

Seeber, R. L., Schmidle, T. B., and Smith, R. S. An Evaluation of the New York State Workers' Compensation Pilot Program for Alternative Dispute Resolution. Albany: New York State Workers' Compensation Board, 2001.

Senger, J. M. Federal Dispute Resolution: Using ADR with the United States Government. San Francisco: Jossey-Bass, 2003.

Sheppard, B. H., Lewicki, R. J., and Minton, J. W. Organizational Justice: The Search for Fairness in the Workplace. San Francisco: New Lexington Press, 1992.

Sitkin, S. B., and Bies, R. J. "Social Accounts in Conflict Situations: Using Explanations to Manage Conflict.” Human Relations, 1993, 46 (3), 349-370.

Slaikeu, K. A., and Hasson, R. H. Controlling the Costs of Conflict: How to Design a System for Your Organization. San Francisco: Jossey-Bass, 1998.

Spencer, D. G. "Employee Voice and Employee Retention." Academy of Management Journal, 1986, 29 (3), 488-502.

Stone, K.V.W. "Employment Arbitration Under the Federal Arbitration Act." In A. E. Eaton and J. H. Keefe (eds.), 1999 Industrial Relations Research Association Research Volume: Employment Dispute Resolution and Worker Rights in the Changing Workplace. Champaign, Ill.: Industrial Relations Research Association, 1999.

Tajalli, H., and Wright, W. A. Evaluation of the Mediation Program of the San Antonio District Office of the U.S. Equal Employment Opportunity Commission. San Antonio, Tex.: Equal Employment Opportunity Commission, 2002.

Tajalli, H., and Wright, W. A. Analysis of Charges of Employment Discrimination Identified as Candidates for Mediation in the San Antonio District Office of the U.S. Equal Employment Opportunity Commission. San Antonio, Tex.: Equal Employment Opportunity Commission, 2003.

Tyler, T. "What Is Procedural Justice? Criteria Used by Citizens to Assess the Fairness of Legal Procedures." Law and Society Review, 1988, 22 (1), 103-135.

U.S. General Accounting Office. Employment Discrimination: Most Private-Sector Employers Use Alternative Dispute Resolution. Washington, D.C.: U.S. General Accounting Office, 1995.

U.S. General Accounting Office. Alternative Dispute Resolution: Employers' Experiences with $A D R$ in the Workplace. Washington, D.C.: U.S. General Accounting Office, 1997.

Ury, W., Brett, J., and Goldberg, S. Getting Disputes Resolved: Designing Systems to Cut the Cost of Conflict. San Francisco: Jossey-Bass, 1989.

Varma, A., and Stallworth, L. E. "The Use of Alternative Dispute Resolution Mechanisms in the Workplace: An Empirical Study." Alternative Dispute Resolution in Employment, 2001, 12 (3), 71-79.

Varma, A., and Stallworth, L. E. "Participants' Satisfaction with EEO Mediation and the Issue of Legal Representation: An Empirical Inquiry." Employee Rights and Employment Policy Journal, 2002, 6 (2), 387-418. 
Waldman, E. A. "The Evaluative-Facilitative Debate in Mediation: Applying the Lens of Therapeutic Jurisprudence." Marquette Law Review, 1998, 82 (1), 155-170.

Wall, J. A., and Lynn, A. "Mediation: A Current Review." Journal of Conflict Resolution, 1993, 37 (1), 160-194.

Youngblood, S. A., Trevino, L. K., and Favia, M. "Reactions to Unjust Dismissal and Third-Party Dispute Resolution: A Justice Framework." Employee Responsibilities and Rights Journal, 1992, 5 (4), 283-307.

Zack, A. M. "Can Alternative Dispute Resolution Help Resolve Employment Disputes?” International Labour Review, 1997, 136 (1), 95-108.

Zweibel, E., and Macfarlane, J. "Systemic Change and Private Closure in Human Rights Mediation: An Evaluation of the Mediation Program at the Canadian Human Rights Tribunal." Unpublished manuscript, 2001.

Zweibel, E., Macfarlane, J., and Manwaring, J. "Negotiating Solutions to Workplace Conflict: An Evaluation of the Public Service Staff Relations Board Project." Unpublished manuscript, 2001.

Lisa B. Bingham is the Keller-Runden Professor of Public Service at the Indiana University School of Public and Environmental Affairs. 